\title{
Pemberdayaan masyarakat melalui penerapan teknologi pengawetan dan pengolahan batang sawit untuk bahan baku mebel dekoratif
}

\author{
Fakhri*, Alfian Malik, Pedia Aldy, Elianora, \& Zulkifli \\ Universitas Riau \\ * fakhriur@gmail.com
}

\begin{abstract}
Abstrak. Batang sawit merupakan salah satu biomassa yang belum termanfaatkan dan menjadi limbah di lokasi bekas peremajaan kebun sawit. Penerapan teknologi pengolahan batang sawit untuk bahan baku mebel dapat memberikan solusi kepada khalayak sasaran untuk dimanfaatkan dan dikembangankan di masa yang akan datang. Tujuan kegiatan pengabdian adalah pendampingan pengolahan batang sawit untuk produksi mebel yang memiliki ciri khas, dan bernilai jual tinggi. Metode penerapan kegiatan yakni pendampingan secara teoritis dan praktek langsung kepada khalayak sasaran tentang teknologi pengolahan batang sawit untuk produk mebel dekoratif. Alat ukur ketercapaian terdiri dari pemahaman teoritis dan kesesuaian aplikasi di lapangan. Hasil kegiatan dapat diimplementasikan berbagai prototype produk mebel. Pengetahuan mitra terhadap usaha pengetaman kayu menjadikan transfer IPTEK pemanfaatan batang sawit lebih mudah diterapkan. Secara sosial ekonomi bagi masyarakat tempatan merupakan hal yang sangat bermanfaat karena dapat merubah persepsi terhadap eksistensi batang sawit yang selama ini dianggap sebagai limbah menjadi suatu potensi yang dapat dimanfaatkan untuk suatu produk bernilai secara ekonomis.
\end{abstract}

Kata kunci: batang sawit, replanting, mebel dekoratif, pengawetan

\begin{abstract}
Oil palm trunk is one of the biomass that has not been utilized and becomes waste in the former oil palm replanting location. The application of palm oil processing technology for furniture raw materials can provide solutions to target audiences to be utilized and developed in the future. The aim of the community service activity is to assist the processing of oil palm stems for the production of furniture that has distinctive features and high selling value. The method of implementing the activity is theoretical assistance and direct practice to target audiences regarding palm oil processing technology for decorative furniture products. Achievement measurement tools consist of theoretical understanding and application suitability in the field. The results of these activities can be implemented by various prototypes of furniture products. The partner's knowledge of the wood processing business makes the transfer of science and technology for the use of oil palm trunks easier to implement. Socio-economically for the local community is very beneficial because it can change the perception of the existence of palm oil stems which have been considered as waste into a potential that can be utilized for an economically valuable product.
\end{abstract}

Keywords: oil palm trunk, replanting, decorative furniture, preservation

To cite this article: Fakhri., A. Malik., P. Aldy., Elianora., \& Zulkifli. 2020. Pemberdayaan masyarakat melalui penerapan teknologi pengawetan dan pengolahan batang sawit untuk bahan baku mebel dekoratif. Unri Conference Series: Community Engagement 2: 241-245. https://doi.org/10.31258/unricsce.2.241-245

(C) 2020 Authors

Peer-review under responsibility of the organizing committee of Seminar Nasional Pemberdayaan Masyarakat 2020 


\section{PENDAHULUAN}

Kegiatan peremajaan lahan sawit menyisakan biomassa padat batang sawit. Peremajaan lahan sawit di lapangan dilakukan dengan berbagai cara. Berdasarkan Peraturan Menteri Pertanian Republik Indonesia Nomor 18/Permentan/KB.330/5/2016 Tentang Pedoman Peremajaan Perkebunan Kelapa Sawit dinyatakan bahwa penanganan limbah batang sawit dilakukan dengan cara dicacah setebal 5 sampai $20 \mathrm{~cm}$ dengan bantuan mekanis alat berat. Hal ini bertujuan untuk menekan resiko serangan hama O.rhinoceros, dan mengurangi penyebaran penyakit Ganoderma sp. Namun, bagi sebagian besar masyarakat pemilik lahan sawit, hal ini sangat memberatkan dan tidak mampu menyediakan anggaran untuk itu. Realita di lapangan, sebagian masyarakat pemilik lahan melakukan penyuntikan zat racun ke dalam batang pohon hidup untuk mematikan dan melapukkan batang pohon sawit untuk meminimalisir biaya operasional penumbangan, namun hal tersebut juga memberikan dampak negatif terhadap lingkungan serta tidak memberikan manfaat terhadap nilai ekonomi masyarakat.

Luas areal kebun Sawit di Indonesia pada tahun 2017 sudah mencapai 14,677 juta Ha. Lahan terbanyak berada di Provinsi Riau yakni 2,703 juta Ha. atau 18,2 \% dari luas lahan di Indonesia (Hendaryati dan Yanuar (Ed.), 2018). Desa Pancurangading merupakan salah satu desa kawasan kebun sawit Sei Galuh. Pemilik lahan sawit didominasi oleh PTPN V, perusahaan swasta PT. Rama-rama, serta lahan masyarakat pola PIR. Luas lahan sawit di wilayah Kecamatan Tapung lebih dari 30.000 Ha (Data Dinas Perkebunan Kabupaten Kampar, 2017). Kondisi masyarakat sasaran dapat dikatakan sudah mapan secara ekonomi karena rata rata masyarakat memiliki lahan sawit minimal seluas $2 \mathrm{Ha}$. Namun karena pohon sawit berumur semakin tua dan sudah tidak produktif lagi, pendapatan masyarakat semakin menurun. Berdasarkan estimasi luas lahan sawit di Tapung sebanyak $30.000 \mathrm{Ha}$, apabila siklus 30 tahunan dilakukan peremajaan secara bertahap, jika satu batang sawit menghasilkan Rp. 500.000 dimanfaatkan sebagai produk komersial, maka jumlah batang sawit yang dapat dimanfaatkan tiap hari sebagai bahan baku sebesar $(30.000 /(30 \mathrm{X} 365))=2,7 \mathrm{Ha}$ per hari. Estimasi nilai ekonomi sebesar: 2,7 x 100 × $500.000=$ Rp. 136 juta rupiah/hari. Berdasarkan potensi ketersediaan limbah kelapa sawit tersebut, maka salah satu arah kebijakan pelaksanaan pembangunan perkebunan kelapa sawit di Provinsi Riau adalah upaya pemanfaatan limbah kayu batang sawit sebagai bahan baku industri perkayuan (Zulher, 2012), aspek pemanfaatan potensi batang sawit tersebut diharapkan dapat mengantisipasi kelangkaan kayu saat ini, kelangkaan bahan kayu komersial telah berimplikasi pada semakin merosotnya kelangsungan usaha di bidang pengolahan kayu industri sawmill dan usaha ikutannya seperti usaha mebel dan pertukangan (Fakhri Dkk. 2015).

Kajian aspek pemanfaatan batang sawit telah banyak dilakukan oleh peneliti, hasil penelitian Balfas (2006) diperoleh nilai kerapatan papan sawit bervariasi antara $0,21 \mathrm{sampai} 0,67 \mathrm{gram} / \mathrm{cm}^{2}$. Hasil uji terhadap sifat mekaniknya diperoleh berkisar antara $288 \mathrm{~kg} / \mathrm{cm}^{2}$ sampai $763 \mathrm{~kg} / \mathrm{cm}^{2}$. Hasil aplikasi produk papan laminasi batang sawit telah dilakukan oleh Fakhri dan Morena (2006), produk papan komposit laminasi yang dihasilkan secara visual dapat menampilkan kesan yang indah dan menawan. Hartono Dkk (2011) menyatakan bahwa tingkat kompresi papan sawit meningkat dari luar ke tengah penampang batang. Mutu papan sawit dapat ditingkatkan dengan menggunakan pengeringan cepat (Fakhri dkk, 2013). Pada tahun 2015 Proses pengawetan batang sawit juga sudah mendapat Paten nomor IDP00003808 oleh inventor Fakhri dan Morena. Okai Et al. (2015) menyatakan bahwa berdasarkan sifat mekaniknya, batang kelapa sawit bisa digunakan untuk produk yang dikenai beban ringan seperti meja kopi, meja tengah, plafon dan panel dinding.. Hasil kajian terhadap pemadatan batang sawit diperoleh bahwa bagian tengah penampang batang dapat dimampatkan menjadi $67 \%$ pada kondisi kering udara dan $72-73 \%$ pada kondisi basah dan kondisi jenuh air dari ketebalan awalnya. Hasil penelitian Fakhri Dkk. (2016) diperoleh bahwa kadar air papan kelapa sawit yang baru ditebang diperoleh sangat tinggi dengan kisaran antara 342\% sampai 523\%, sehingga sangat berpotensi untuk berkembangnya jamur pada periode awal penebangan sampai pengolahan batang sawit. Hasil pengawetan batang sawit menggunakan bahan pengawet Biocide menunjukkan hasil yang efektif untuk mencegah jamur biru (blue stain).

Perkebunan sawit di kawasan Kecamatan Tapung termasuk wilayah Desa Pancurangading saat ini sudah mencapai umur pohon sawit di atas 30 tahun dan sebagian sudah diremajakan. Sampai saat ini, di berbagai lahan bekas replanting tidak dimanfaatkan sehingga menjadi limbah terbuang. Di sisi lain, kelangkaan bahan kayu komersial berimplikasi pada semakin merosotnya kelangsungan usaha di bidang pengolahan kayu (industri sawmill dan usaha ikutannya seperti usaha mebel dan pertukangan). Limbah OPT hasil tebangan lahan sawit tersebut akan terus bertambah banyak. Di sisi lain, masyarakat tidak memahami tentang cara penanganannya. Oleh karena itu perlu dilakukan pendampingan kepada masyarakat tentang aspek 
pemanfaatan limbah batang sawit agar dapat dioptimalkan dan memiliki nilai tambah secara ekonomis. Teknologi yang diperlukan agar OPT termanfaatkan adalah teknik pengawetan dan teknologi kayu komposit (coating dan laminasi) untuk meningkatkan mutu bahan baku. Dengan adanya pemahaman yang dimiliki masyarakat nantinya akan dapat dioptimalkan penggunaan limbah tersebut untuk berbagai keperluan masyarakat. Hasil kegiatan diharapkan akan memberikan dampak positif terhadap berbagai aspek kehidupan lainnya di wilayah binaan di masa mendatang, selain dapat memberikan peluang terhadap perekonomian, juga diharapkan dapat menjadi sentra pengolahan batang sawit di masa mendatang.

Tujuan umum kegiatan pengabdian adalah membina masyarakat sasaran tentang cara pemanfaatan potensi batang sawit untuk mampu diolah menjadi produk komersial. Tujuan khusus adalah kegiatan pendampingan masyarakat sasaran untuk mengoptimalkan pemanfaatan bahan batang sawit untuk produksi mebel yang memiliki ciri khas. Tekstur permukaan produk papan kayu sawit memiliki nilai dekoratif yang tidak dimiliki oleh bahan lainnya, sehingga yang dihasilkan memberikan unsur seni dan nilai ekonomis tersendiri.

\section{METODE PENERAPAN}

Metode penerapan kegiatan pengabdian ini yakni pendampingan secara teoritis dan praktek langsung kepada khalayak sasaran. Mitra kegiatan terdiri dari pihak Badan Usaha Milik Desa (BUMDES) sebanyak 3 orang, dan pemilik dan pekerja pada usaha pengetaman kayu milik Bapak Edi Sucipto (4 orang). Pelaksanaan kegiatan dilakukan oleh tim pengabdian kepada masyarakat Universitas Riau skema Program Desa Binaan, dan bersinergi dengan program Kuliah Kerja Nyata mahasiswa Universitas Riau melalui program integrasi. Solusi pemberdayaan masyarakat sasaran dilakukan dengan cara pendampingan bagaimana teknologi pengolahan batang sawit non produktif untuk dimanfaatkan sebagai bahan baku untuk mebel. Beberapa tahapan yang dilakukan yakni: Tahap penebangan batang sawit, tahap pembelahan menjadi papan lembaran, tahap pengawetan papan sawit, tahap pembuatan produk mebel, serta tahap finishing.

Hasil kegiatan pendampingan ini diharapkan dapat memberikan solusi terhadap penanganan limbah sawit menjadi potensi bahan baku alternatif yang sangat menjanjikan untuk diaplikasikan serta memberikan berbagai peluang usaha kepada masyarakat untuk pemanfaatan bahan baku yang ada. Untuk mengukur keberhasilan program dilakukan menggunakan alat ukur ketercapaian terhadap pemahaman teoritis dan ketercapaian demonstrasi di lapangan terhadap kesesuaian penerapan produk mebel yang memiliki ciri khas dan tampilan dekoratif.

\section{HASIL DAN KETERCAPAIAN}

Kegiatan awal dilakukan dengan cara memberikan pembekalan secata teoritis kepada peserta yang dilakukan di Aula Kantor Desa Pancurangading. Kegiatan pemaparan teori dilakukan oleh tim Desa Binaan untuk memberikan penguatan cara pengolahan batang sawit mulai dari penebangan sampai menjadi produk mebel.

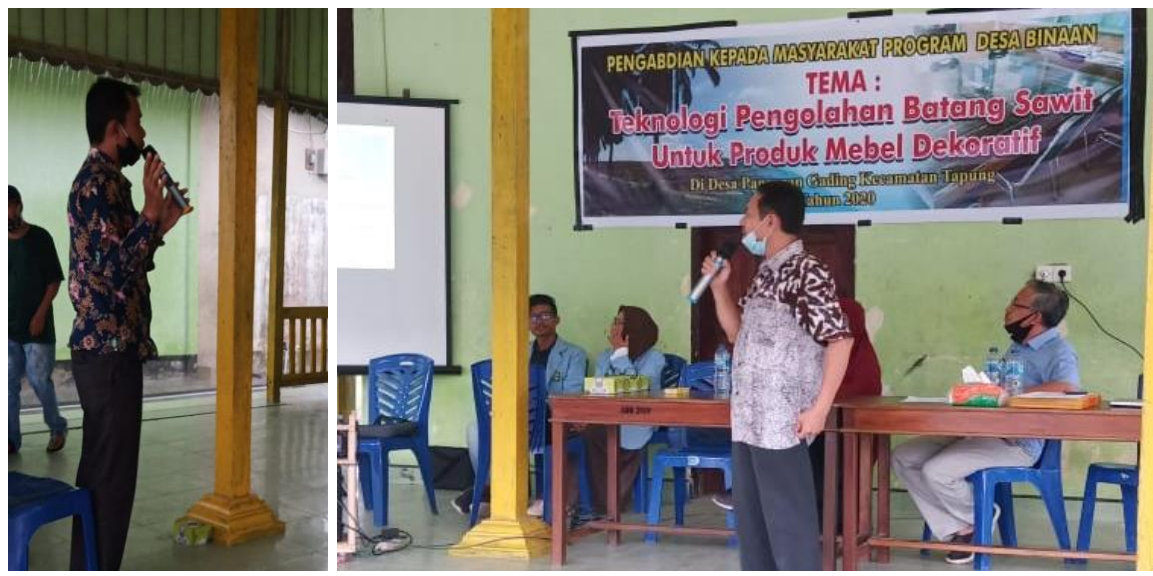

Gambar 1. Penyampaian materi oleh Tim Pengabdian dan Diskusi

Kegiatan pendampingan dilakukan mulai dari penebangan batang sawit. Tahap penebangan, pemotongan batang sawit serta proses pengawetan papan sawit. Tahap penebangan dilakukan dengan mesin gergaji rantai atau chainsaw, dilanjutkan dengan pembelahan menggunakan mesin circularsaw yang dimodifikasi pada mesin mobil, sehingga dapat dibawa ke lokasi lahan sawit yang akan. Adapun mesin gergaji circularsaw 
tersebut selama ini hanya diperuntukkan untuk mengolah kayu masyarakat untuk bahan kayu bangunan (Gambar 2). Proses selanjutnya adalah pengawetan papan sawit hasil olahan. Tahaup ini merupakan tahap yang sangat penting karena kelemahan batang sawit adalah mudah berjamur. Segera setelah dijadikan papan lembaran, dilanjutkan proses pengawetan menggunakan bahan pengawet komponen Biocide dengan cara disemprot sebagaimana terlihat pada Gambar 2.
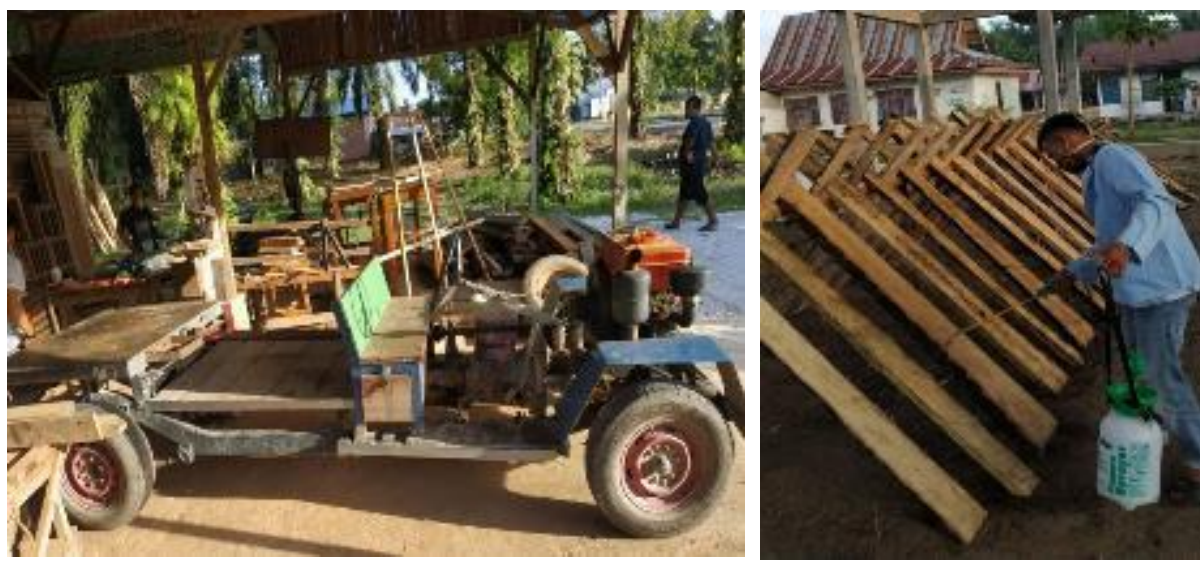

Gambar 2. Proses Pengolahan Batang Sawit; Mesin Gergaji Pengolah Batang Sawit (kiri); Proses Pengawetan Papan Sawit Hasil Olahan (kanan)

Setelah proses pengeringan papan sawit sudah mencapai kadar air kering udara, maka sudah dapat dibuat produk mebel. Hasil pembuatan produk mebel yang telah dibuat dapat menghasilkan produk yang bernilai seni karena tampilan visual serat sawit yang khas memiliki nilai dekoratif (Gambar 3).
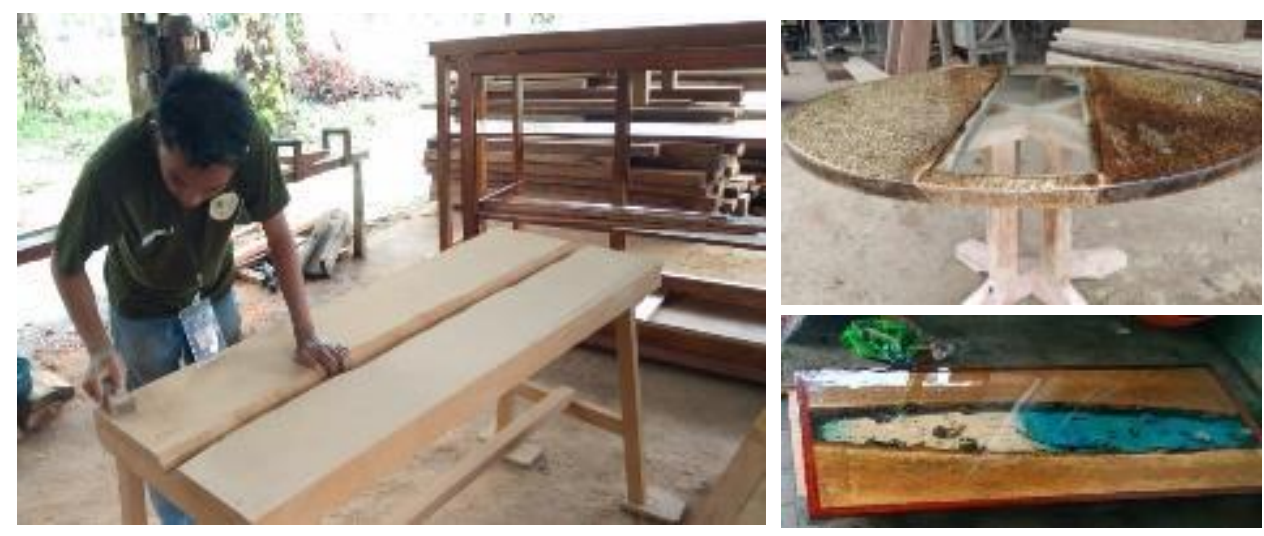

Gambar 3. Kegiatan Finishing Produk Mebel (kiri), Hasil Varian Produk Mebel Dari Batang Sawit (kanan)

Hasil pengabdian kepada masyarakat yang telah dilaksanakan dapat memberikan suatu nilai tambah bagi masyarakat, dari segi pengetahuan teknis, masyarakat sasaran telah dapat memahami cara dan tahapan proses pengolahan batang sawit sampai membuat produk mebel. Ditinjau dari segi perubahan perilaku sosial ekonomi dapat dikatakan bahwa adanya kegiatan ini dapat memberikan pemahaman yang berbeda bagi masyarakat tentang persepsi terhadap persoalan limbah batang sawit yang bagi masyarakat pada awalnya merupakan limbah yang mengganggu dan mencemari lingkunngan menjadi suatu potensi untuk dimanfaatkan sebagai produk yang akan dapat bernilai ekonomi tinggi. Bagi perguruan tinggi, kegiatan ini merupakan bagian dari upaya penerapan hilirisasi hasil hasil penelitian untuk dapat diimplementasikan pada kondisi nyata di lapangan serta adanya kerjasama yang saling menguntungkan di masa yang akan datang.

Kegiatan pengabdian yang telah dilakukan terhadap khalayak sasaran telah dapat berlangsung dengan lancar karena pihak mitra memiliki pengalaman teknis usaha pengolahan kayu, sehingga menjadi mudah untuk memberikan suatu penerapan teknologi pengolahan bahan batang sawit. Hasil yang dirasakan mitra bahwa secara teknis, pengolahan menggunakan mesin modifikasi (Gambar 2) cukup ekonomis dilakukan, namun masih perlu penyesuaian aksesoris untuk pengolahan batang sawit. 


\section{KESIMPULAN}

Hasil kegiatan yang telah dilakukan dapat disimpulkan sebagai berikut:

1. Kegiatan pengabdian ini telah dapat diimplementasikan kepada mitra sehingga dapat dihasilkan berbagai prototype produk mebel.

2. Pengetahuan mitra terhadap usaha pengetaman kayu menjadikan transfer IPTEK pemanfaatan batang sawit lebih mudah diterapkan.

3. Secara sosial ekonomi bagi masyarakat tempatan merupakan hal yang sangat bermanfaat karena dapat merubah persepsi terhadap eksistensi batang sawit yang dianggap sebagai limbah menjadi suatu potensi yang menjanjikan dan dapat dimanfaatkan untuk suatu produk bernilai ekonomis.

4. Hasil produk mebel yang telah dibuat, perlu dilakukan pengembangan varian serta survey pasar untukmemperoleh masukan dari pihak pemakai untuk memperoleh umpan balik terhadap kekurangan produk.

\section{UCAPAN TERIMA KASIH}

Ucapan terima kasih disampaikan kepada Ketua beserta staf Lembaga Penelitian dan Pengabdian kepada Masyarakat (LPPM) Universtas Riau yang telah memberikan pendanaan program pengabdian kepada masyarakat skema Desa Binaan tahun 2020.

\section{DAFTAR PUSTAKA}

Balfas, J. 2006. New Approach to Palm Oil Wood Utilization for Woodworking Production. Journal of Forestry Research, 3(1), 55-65.

Fakhri dan Morena, 2009, Pemanfaatan Limbah Batang Sawit sebagai Produk Papan Komposit Laminasi untuk Bahan Panil Dekoratif, Laporan Penelitian SDPF-Forum Heds, Jakarta.

Fakhri, Haji Gussyafri, dan Yohanes, 2015, Kajian Potensi Limbah Kayu Industri Sawmill untuk Produk Panel Ringan Berongga, Proseding $1^{\text {st }}$ Annual Civil Engineering Seminar 2015 (ACES 2015), Pekanbaru.

Fakhri, Elianora, Eko Riyawan, 2016, Pengendalian Jamur Biru (Blue Stain) Batang Kelapa Sawit Limbah Replanting Menggunakan Bahan Pengawet Biocide, Proseding Pelestarian Lingkungan PSIL, 2016

Hartono, R., I. Wahyudi. F. Febrianto. W. Dwianto. (2011). Pengukuran Tingkat Pemadatan Maksimum Batang Kelapa Sawit. J. Ilmu dan Teknologi Kayu Tropis, 9(1), 73-83.

Hendaryati, D. D. dan Y. Arianto. (Eds.). 2018. Statistik Perkebunan Indonesia 2017 - 2019. Jakarta: Sekretariat Direktorat Jenderal Perkebunan, Direktorat Jenderal Perkebunan Kementerian Pertanian.

Naufa, M., H. P. Limbong. 2019, Pemanfaatan Serat Batang Kelapa Sawit Sebagai Lembaran Serat Semen. Jurnal Teknik Dan Teknologi, 14(28), 40-48.

Okai, R., S. J. Mitchual., P. Mensah., R.1 K. Dzakpasu. (2015). Characterization of Physical, Machining and Finishing Properties of Oil Palm Lumber: An Emerging Non-Timber 1Forest Product in Sub-Saharan Africa. International Journal of Emerging Technology and Advanced Engineering, 5(8), 289-296. www.ijetae.com

Zulher. 2012. Kebijakan Pembangunan Perkebunan Kelapa Sawit di Provinsi Riau; dalam Suwondo dan Sukemi, I.S., $(E d s)$, Perkebunan Kelapa Sawit Berkelanjutan untuk Kesejahteraan Masyarakat. Pekanbaru: UNRI Press. 